\title{
DIFFERENCES IN LEARNING OUTCOMES FOR THE ONLINE AND F2F VERSIONS OF "AN INTRODUCTION TO SHAKESPEARE"
}

\author{
Mary Ann Koory, Ph.D. \\ University of California Berkeley Extension Online \\ 2000 Center Street, Suite 400 \\ Berkeley, CA 94704-9907 \\ (510)642-4124 \\ bardunex@earthlink.net
}

\begin{abstract}
The same course in both an online and on-campus environment makes for an extended experimental comparison of learning outcomes, while controlling for two important variables: the instructor and the content of the course Students learn course content through four kinds of encounters-alone, one-to-one, one-to many, and many-to many.
\end{abstract}

The online version of "Introduction to Shakespeare" course has consistently better learning outcomes than the on-campus version, as a result of the compelling nature of the one-to-one communication mode online and the textual nature of the many-to-many and one-to-many modes online. Text-based communication in the online class reinforces the skills pertinent to a literature class. Other crucial factors are online pedagogy and the self-selection. Ultimately, the differences between the online and F2F classrooms may be less crucial to learning outcomes than the degree to which the course design, regardless of technological environment, develops and supports students' abilities to practice adult learning styles.

\section{KEYWORDS}

Pedagogy, Learning Effectiveness, Student Satisfaction, Text-based Communication

\section{INTRODUCTION}

From 2000-2002, I taught University of California Berkeley Extension Online English XB17, "Introduction to Shakespeare," and simultaneously taught the on-campus equivalent, English 17, as a lecturer for U.C. Berkeley's English Department. Teaching the same class in both an online and oncampus environment makes for an extended experimental comparison of the learning outcomes of an online class directly against its on-campus equivalent, while controlling for two important variables: the instructor and the content of the course.

In the analysis that follows, I organize a set of disparate observations according to four basic encounters or communication modalities in which students learn (or have the opportunity to learn) course content:

1) one-alone: the student alone with course texts;

2) one-to-one: student and teacher communicate;

3) one-to-many: communication between the teacher and the class as a whole 
4) many-to-many: students communicate among themselves.

A matrix like this allows me to consider the varying impact of similar factors, even when the overall learning outcomes appear to be equivalent.

I believe that the online version of my "Introduction to Shakespeare" course has consistently better learning outcomes than the on-campus version, as a result of the compelling nature of the one-to-one communication mode online and the textual nature of the many-to-many and one-to-many mode online. Part of this result may be specific to the course content: Text-based communication in the online class reinforces the skills pertinent to a literature class. Another crucial factor in the difference in learning outcomes is the interaction between pedagogical biases of the online classroom and the self-selected nature of students taking an online distance education Shakespeare class through University of California Berkeley Extension Online. Those who complete the online class are often the "very models" of Malcolm Knowles' description of an adult learner-experienced, self-directive, task-oriented, interested in problem-solving and immediate application. These learners thrive in the online classroom environment. Ultimately, the differences between the online and F2F classrooms may be less crucial to learning outcomes than the degree to which the course design, regardless of technological environment, develops and supports students' abilities to practice adult learning styles.

\section{DESCRIPTION OF THE COURSES UNDER DISCUSSION}

I have taught University of California Berkeley Extension Online English XB17, "Introduction to Shakespeare," since 1997. I wrote and designed the course, which represents the Extension Online version of the U.C. Berkeley English Department's on-campus English 17, "An Introduction to Shakespeare." From 2000-02, I simultaneously taught the traditional F2F on-campus version of English 17 five times as a lecturer for U.C. Berkeley's English Department.

\section{A. Course Content}

Both courses offer 4 units of U.C. credit and the course description in the respective catalogs are identical: They are both "lower level literature courses that focus on five of Shakespeare's plays as literature of immense cultural importance and also as popular entertainment, both in Shakespeare's day and in our own. They are designed to give students a better understanding and appreciation of Shakespearean language and literary forms and a critical awareness of the continuing usereinterpretation or reinvention-of Shakespeare's plots and characters, even in our own time." I varied a few of the five core plays for my on-campus course.

The on-campus course, limited by the high enrollments, made use of lectures and general discussion, with regular in-class writing assignments, papers and exams.

The online course makes use of the following features:

- Approximately 40,000 words of online lecture notes

- Online directions for 14 separate written assignments

- 20 separate Message Boards for students to post assignments for other students and the instructor to read, respond to and conduct extended discussion of specific topics.

- A webliography: list of 50 web-based resources applicable to individual plays, to Shakespeare studies and Renaissance culture more generally, for instance: electronic editions of the plays and 
sites with historical and cultural information, e.g., one site devoted to Renaissance weddings and another to Renaissance taverns.

- "Optional Shakespeare Explorations:" assignments that invite students to visit and assess pertinent web sites, for instance, the Globe Theater site that features a three-dimensional virtual tour of a present-day replica of the theater in which Shakespeare's company performed. Students can thus pursue interests that are related to but beyond the scope of the course, with the instructor's guidance.

- Occasional "office hour" online chats: One hour chat room meetings, optional, designed for drop-in discussion of content and procedure, scheduled on as needed basis.

- Online self-grading quizzes: A "benchmark" quiz students take as they begin the course, to test their general knowledge of Shakespeare and any preconceptions they may have, and then take again at the end of the course to see what has changed; and a practice identification quiz in preparation for the final, that presents different passages for students to identify.

\section{B. Chronological Structure}

Online students may take up to six months to complete the course, and turn in assignments when they wish during that asynchronous time frame. Continuous enrollment means that any point in time students are beginning, continuing or completing the course, with a different start and stop date for each student. The on-campus course took place over a semester according to a standard cohort fixed-date structure; assignments and exams were due on the same date for everyone in the class; students attended class lectures and discussion together in the same place at the same time.

\section{Student Populations/Class Size}

Besides the obvious differences in chronological structure, logistics and classroom environment, the major difference between the courses was in the number and kinds of students.

The size of my on-campus class was anywhere from 4 to 19 times as large as the online group, and consisted of mostly traditional age undergraduates working towards their B.A. The classes ranged from 50 to nearly 200 students, with a large (100 plus) lecture being the norm. English 17 on campus is taken by both English majors picking up the Shakespeare requirement for the major and non-English majors fulfilling a humanities requirement.

The online course averages about 12 active students at any one time. My online students are typical of U.C. Berkeley Extension students, mostly college-educated working adults (70\% of Extension students generally are age 26 through 49). Students in my class range from experienced literature teachers continuing their professional development, to traditional undergraduates picking up a requirement, to advanced high school students, to lifelong learners indulging in an interest in Shakespeare.

\section{ANALYTICAL FRAMEWORK}

I've adapted a scale of "communication paradigms" for computer-mediated communication in the classroom proposed by Morten Flate Paulsen as a framework for understanding the value of each modality in an online and traditional classroom [1]. It covers, relatively comprehensively, the encounters in which a student may learn something regardless of technological environment. The value or impact of these communication modalities on student learning will vary according to the student, the instructor, the class and the environment; my experience controls for two variables: the instructor and the course. 
Below are Paulsen's terms with my adaptation and generic examples.

1. One-alone: the student alone encounters course texts (e.g., plays, videos, essential course content)

2. One-to-one: teacher to student (e.g. assignments, questions, office hours )

3. One-to-many: teacher to class as a whole or one student to class as a whole (e.g. lectures, syllabi; student presentations; )

4. Many-to-many: students communicate among themselves in groups or in general discussion, with guidance and input from the teacher. (e.g. group presentations or classroom discussion)

\section{Note on Data}

In the analysis following, I use standard, anonymous institutional student evaluations of both courses and a set of questionnaires I designed and sent out to students after they complete the course. Those are not anonymous, and students know that I will be reading them as feedback on the course and my teaching. I use my own questionnaires for qualitative descriptions of aspects of the course, and most of the statistics and the occasional citation from the anonymous surveys, as noted.

- U.C. Berkeley English Department, Course Evaluations, English 17, 2000-2002 (350 anonymous) (UCBED)

- U.C. Berkeley Extension Online Course Evaluations, XB17, 2000-2001 (24 anonymous) (UCBXO)

- M.A. Koory database of feed-back questionnaires, 2001-2003 (12 signed surveys) (KDB)

\section{ONE-ALONE: STUDENT ENCOUNTERS WITH COURSE TEXTS}

The flexible, asynchronous schedule of the online Shakespeare course allows students to spend a variable amount of time on the texts, according to their needs.

Online Value of One Alone Communication Mode: Medium

F2F Value of One Alone Communication Mode: Medium

\section{A. One-Alone Mode Definition}

I am using the term "texts" because in an "Introduction to Shakespeare" literature course, we primarily study texts, printed and web-based. But "text" is widely applicable: it includes primary literary texts (a selection of 5 plays of Shakespeare, poetry of different authors), audio-visual presentations of Shakespeare plays, and Internet web sites for both my online and F2F classes.

\section{B. Self-Pacing}

The online course allows students to pace themselves according to their needs vis a vis the material. Fixed-date cohort classes do not allow for self-pacing. An online student who needed a slow pace explains: "I developed a greater comfort with the text in the online course because I spent a greater amount of time with the text. The time constraints of an on-campus class limited me from spending more time with text." (KDB) And an online student who wanted a quicker pace concurs: "Because a classroom setting constricts students who are more interested or learn quicker than others to an average student's 
pace, a great deal of importance in understanding and analyzing is left behind. In the online class I was able to learn at a faster pace ..." (KDB)

\section{PERSONAL PRESENCE IN ONE-TO-ONE AND ONE-TO-MANY MODES}

In the discussion of one-to-one and one-to-many modes that follow, I omit the assessment of an intangible but powerful factor in teaching and learning: the personal presence or personality of the teacher. We are used to projecting our teacherly personae in a live classroom; it requires, however, a different set of skills in a text-based online classroom. Katrina Meyer notes:

"Being able to express one's personality, or "presence," is another intriguing skill that may impact the creation of satisfactory learning communities, and could become a necessary new skill for online conversations. Certainly, with the loss of facial expressions, voice intonations and gestures, important nonverbal meaning and shadings of meaning are lost. Yet, there is evidence that a personal presence-as captured by one's written expression-is important in web-based classes." [2]

Meyer's evidence vastly understates the case, I believe, no doubt because "personality" is a largely subjective factor difficult to measure in the context of education as a social science. Whether I am projecting my pedagogical persona "live and in person" or strictly through computer-generated text, it can have a terrific impact on students' motivation, self-image, and valuation of course content, all of which in turn will have a significant impact on student learning. One major barrier to taking an online distance education course (beside technological hurdles), for instance, is prospective students' perceptions that they won't have any personal interaction with the teacher. I myself wondered whether students who never meet me in person would perceive a remote, austere individual when mediated through the computer, unlike the relatively approachable style I tend to have in the F2F classroom.

To my surprise, my personal presence does not appear to have significantly different impact-in degree or quality -in the two different environments. Students speak positively of my personal presence in evaluations of both the online and on-campus courses and strikingly, use many of the same adjectives (e.g., "open", "accessible", "humorous" UCBXO, UCBED).

\section{ONE-TO-ONE: INDIVIDUAL EXCHANGES BETWEEN STUDENT AND TEACHER}

One-to-one exchanges between teacher and student generally have high impact on student learning in both online and on-campus environments; in my online class, however, it is the requisite mode for our communication, whereas in the on-campus class, direct communication with me was optional. Moreover, all one-to-one communication online occurs as text. The act of composing responses to course content makes one-to-one communication online more substantive than ephemeral in-person encounters. As a result, this mode offers higher value for my online Shakespeare students than those in the F2F classroom.

Online Value of One-to-One Communication: High

F2F Value of One-to-One Communication: Low 


\section{A. One-to-One Mode Definition}

In the online Shakespeare course, I respond to students in reference to their assignments and other courserelated questions and comments directly via email and occasionally use "office hour" chat rooms. In a F2F class, this mode would include written feedback on assignments and office hour consultations.

\section{B. More Student Writing Online}

Online Shakespeare students write significantly more than the students in the face-to-face classroom. Writing makes our one-to-one communication generally more thoughtful than in-person, occasionally rushed and casual exchanges that happen on-campus. In an English class, the increased practice in writing about literary texts and related issues perceptibly enhances the students' skills in writing critical discursive prose and reading literary texts analytically.

Not counting the final exam, using a conservative estimate, the online course requires students to write 5,250 words, about $26 \%$ more written work than the 3,875 written words required in the F2F course.

\begin{tabular}{|l|l|l|}
\hline \multicolumn{3}{|c|}{ Table 1: O/L vs. F2F "Introduction to Shakespeare" Course Work } \\
\hline & O/L Shakespeare & F2F Shakespeare \\
\hline Written Assignments & $14(250-500$ wds $)$ & 1 5-pp paper $(1000$ wds $)$ \\
\hline Quizzes & $\begin{array}{l}2 \text { online multiple } \\
\text { choice }\end{array}$ & $\begin{array}{l}5 \text { in-class essays }(250-500 \\
\text { wds ea. })\end{array}$ \\
\hline Mid-term Exam & None & 1 take-home (1000 words) \\
\hline Final Exam & 3 hours: i.d.s, essays & 3 hours: i.d.s, essays \\
\hline $\begin{array}{l}\text { Total Words Required } \\
\text { (exclusive of final) }\end{array}$ & $\mathbf{5 , 2 5 0}$ words & $\mathbf{3 , 8 7 5}$ words \\
\hline
\end{tabular}

\section{More Feedback From The Teacher Online}

By the same token, online students receive a great deal more written feedback from me. They receive detailed comments from me on their assignments at least 6 times during the course (700-1000 words total for my feedback during the online course), making for more frequent and substantive exchanges between instructor and individual student.

$100 \%$ of the online students surveyed "agreed" or "strongly agreed" that I answered questions and provided feedback that was helpful to the student's learning. $86 \%$ reported that the amount of interaction with me was "about right," and only 14\% reported that interaction was "too little." (UCBXO)

Direct one-on-one interaction between me and my students in the on-campus Shakespeare lectures occurred significantly less often and with significantly fewer students than in the online course. First, as is typical of larger universities, graduate student readers graded and commented on all of the undergraduate students' written work in the on-campus course. My F2F Shakespeare students never received written feedback from me. Second, the majority of my on-campus students did not engage me in one-to-one communication. I held two-hour weekly in-person office hours, and responded briefly to questions before and after lecture. Over the course of the semester, I spoke with approximately $20 \%$ of the students in these large classes. Perhaps another $10 \%$ sent me email messages, an option I also made available.

An online student of mine compares one-to-one communication online with her traditional undergraduate 
experience: "I sent in questions and you got back to me when you could. It was much more convenient than hanging around outside a professor's office waiting to be seen, trying to catch him/her after class with twenty other students, or worse, telephoning him/her at home." (KDB) Inconvenience as well as a certain implicit indignity hinders the on-campus one-to-one mode of communication. Students may also feel inhibited about "bothering" teachers F2F. One of my online students admits, "I don't think I would have bothered a face-to-face professor with some of the questions I had [in the online Shakespeare class]. I would have tried to avoid this [in a F2F class]." (KDB) One-to-one communication in my online Shakespeare class is convenient, does not impose any particular indignity on students (e.g., queuing) and most important, is requisite, effectively counter-acting student inhibitions about speaking directly with a teacher.

\section{Technological Environment Less Decisive}

In this case, it's difficult to disentangle the effects of a technological environment that makes one-to-one communication an inherent part of the classroom structure from an institutional policy (the decision to have a large lecture class) that minimizes the one-to-one mode. The logistics involved in providing personal feedback to 50 or more students may actually trump the technological differences between the two environments. Teaching online certainly increases the pedagogical value of one-to-one communication in comparison with F2F classes, but even more so when size of the F2F class minimizes one-to-one communication between teacher and student.

\section{ONE-TO-MANY: TEACHER COMMUNICATES WITH THE CLASS AS A WHOLE}

Although dynamic course content occurs differently in the online and F2F environments, there are no significant differences in content between the online and on-campus course. In my F2F class, students spend 35\% more of all course work receiving my one-to-many communications than do their online counterparts. Online one-to-many communication, however, does not appear to have proportionally less impact. The effectiveness of my lecture notes and "public" comments may even be greater in my online course. First, as web-based text, my notes and posts are continuously available for students' review. Second, some of the time spent by F2F students in the one-to-many mode needs to be discounted as passive "face time." The time online students spend reading lecture notes is likely to be $100 \%$ active "focused time" which increases the effectiveness of those communications.

Online Value of One-to-Many Communication: High

F2F Value of One-to-Many Communication: Medium

\section{A. One-to-Many Mode Definition}

The one-to-many mode includes all of my communications to the class, including my lecture notes, "hand-outs" (e.g., syllabus), clarifications of assignments and course content, and my public responses to students, either posted on Message Boards or spoken at the front of the classroom, that are intended to be read or heard by the rest of the class. (In my "Introduction to Shakespeare Class," students do not make individual presentations to the class, which in other classes would also fall into this category.)

\section{B. Dynamic Elements In Lecture Content}

The web-based lecture notes I wrote in 1997 for the online course remain largely static (due to the high 
cost and time intensity of production), whereas my more recent F2F lectures, though based on the earlier work, necessarily reflect new knowledge and changes in thinking. Such dynamic development (even in a relatively stable field such as the literary study of Shakespeare) occurs in the online course in two areas outside of the lecture notes. The Message Board threaded discussions and my one-on-one exchanges with students reflect recent developments in research, current events and my own thinking. This structure functions analogously to the F2F classroom in which the textbook remains the same over semesters while each class discussion and the teacher's supplementary commentary reflect current thinking and research.

Last Spring, for instance, the disputed authorship of "The Funeral Elegy," a minor Renaissance poem, seems to have been decided conclusively in favor of John Ford, not William Shakespeare, as had been previously asserted by several scholars and discussed in my lecture notes. In June 2002, I opened a Message Board on this topic and posted links to several articles recounting this academic development. Interested students can easily bring themselves up to date. The on-campus equivalent is a short live lecture on the scholarly development, its critical significance, and direction to the same resources I use in the online class.

\section{Students Spend More Time F2F In One-To-Many Mode}

Let's begin this section with a paradox: my on-campus students actually spend more time on "Introduction to Shakespeare" lectures than do their online counterparts; however, the online students do not report significantly less comprehension of or engagement with the content of my lectures and other one-to-many communications.

$57 \%$ of my online students report taking a minimum of between 3 and 4 months to complete the class, most (72\%) spending 2-3 hours a week on course work, for an average of about 42 hours total. (The remaining $28 \%$ spent more time: $14 \%$ reported spending 4-6 hours a week and another $14 \%$ spent 7-10 hours.) (UCBXO) I estimate that 10 hours or $24 \%$ of that average 42 hour total is spent reading and reviewing the lecture notes. A student who attended every one of my F2F Shakespeare lectures would have spent 30 hours receiving one-to-many communication, i.e. lecture. (43 one-hour class periods over one 15 -week semester, minus 5 in-class quizzes and $20 \%$ of the remaining class periods spent in class discussion). Measured in hours, F2F students spent 300\% more time in lecture than their online equivalents, an astonishing disparity in absolute terms. A better measure, I think, is the proportion of the total time students spent receiving one-to-many communication. One-to-many communication makes up $37 \%$ of the total amount of time F2F students spend on "Introduction to Shakespeare," as opposed to an estimated $24 \%$ of the total time an online student spends in the same class (see Table 2).

That difference (24\% vs. $37 \%$ ) in the proportion of time spent in the one-to-many mode does not, however, appear to indicate a proportional difference in the impact of the lectures. And in terms of performance assessment, my online students demonstrate an above-average comprehension of course material (see Table 6).

\section{Entertainment Value Versus Reference Value}

I have always thought of myself as an effective lecturer and doubted that would translate to a medium in which my lectures are downloaded web pages. The potential for the engaging quality of lecture being "lost in the translation" became a major focus in creating the online course. UCBXO production staff used their expertise in web and graphic design (breaking up the lectures into descriptively titled, digestible "chunks" of text, interspersing it with hot links, roll-overs and the occasional animation, and more.) to enhance the "readability" of the notes, while I used low-tech rhetorical techniques to enhance 
the textual content. Online students do report enjoying the style and design of those lecture notes: "I felt that Dr. Koory's style and personality really came through the material and made the course more enjoyable." (UCBXO) "I wouldn't have learned $20 \%$ of what I think I learned if it hadn't been for the tone, clarity, and holistic breadth of the reader." (KDB) Thus, the "entertainment value" of F2F lecture presentations, the interest sparked by tone of voice, style, clarity, and rhetoric can be reproduced to some degree online.

It's gratifying that our creative efforts haven't gone unnoticed by the online students; however, when reporting on the value of the lecture notes, online students actually emphasize a feature that has little to do with their graphic or rhetorical style. One online student describes what she calls "a kinder, gentler kind of lecture": "There were no external distractions, and I read and re-read the lectures until I was absolutely clear, which is not a luxury one has in oral lectures. . . the ability to read the actual lecture as many times as necessary helped me tremendously. Having the entire lecture available for reference at any time is a boon to all student kind." (KDB) The lecture notes are continuously available for review and reflection, two key processes in learning. Moreover, as another student notes, students can study lecture notes when they are ready, unlike a fixed lecture schedule in which students attend class whether or not they are prepared to pay attention. "This, for me, is the main advantage to an online course. Lectures can be taken and reviewed at leisure. Flexibility plays a key role in enabling people to attack the course material when they can focus on it properly." (KDB) The immediate impact of a lively, intellectually challenging F2F lecture, as we all know, dissipates quickly without repetition, reinforcement and review in different communication modes. Lecture notes as web-based text make the review process intrinsic to the one-tomany communication mode, rather than an added, merely potential, step. The "entertainment value" of F2F lectures is supplemented online by what we might call the inherent "reference value" of one-to-many communication, that is, its continuous availability to the student.

\section{E. Face Time Versus Focused Time}

The quantity of time students spent on the lecture element of the two courses needs to be assessed according to the quality of the time. I propose to make a distinction between what might be termed "face time" in a corporate setting, the simple visible and physical presence of a person in the workplace, and what might be called "quality time" in the therapeutic lingo of parenting, that is, the undistracted and active engagement with another person. Because the term "quality time" connotes a range of negative emotions from a distinctly unscientific area, I'd like to use the more neutral term "focused time" when we speak of students' participation in the classroom.

As we step into a F2F classroom, teachers automatically perform an elementary assessment of students' engagement: we look around to see whether students are present and as the class period progresses, whether they look attentive. But while face time may indicate that students are engaged in learning, it's not definitive. Face time means nothing more than a student's ability to answer "here" during roll call and stay awake during lecture. It may indicate active emotional or intellectual engagement in the class or it may indicate a simply physical presence or anything in between. Online, faces are invisible and that minimal presence does not register. The time online students report spending on course work is purely focused time spent reading and responding to the texts, lecture notes, message board postings and working on assignments. Therefore, face time as a measure of active student engagement needs to be discounted according to how much of it might represent higher quality focused time. Focused time represents more efficient use of student time, and makes the teacher's one-to-many communication more effective. 


\section{MANY-TO-MANY: CLASSROOM DISCUSSION}

Due to universal participation and composed contributions, classroom discussion online offers more substance and more diverse points of view than F2F classroom discussions. In an asynchronous online environment, however, discussions may lack spontaneity and sustained dialogue.

Online Value of Many-to-Many Communication: Medium

F2F Value of Many-to-Many Communication: Medium

\section{A. Many-to-Many Mode Definition}

Classroom discussion among students and teacher constitutes the many-to-many communication in my classes; there are no group presentations and little small group activity in my lecture classes. Online, classroom discussion occurs as individuals post messages to topic-specific message boards; students are required to make a minimum number of posts. At this moment, there are 20 different threads (topic specific discussions), consisting of 147 total posts with around 34,000 words altogether on the Message Boards.

\section{B. Active and Passive Benefits to Threaded Message Board Discussions}

$86 \%$ of my online students surveyed "agreed" that "message board threaded discussions stimulated learning and discussion." (UCBXO) As in the one-to-many communication mode, classroom discussions offer students opportunities to learn passively and actively. Both modes are available to online and F2F students; however, active participation in class discussion is required in the online Shakespeare class while optional in the F2F class. That simple distinction adds great value to online student discussion.

I track the number of my online students' logins to the Message Boards using our Web Board program, and I've found that students who complete the Shakespeare course login to the Message Boards at least twice per week, 50-70 times altogether over the length of the course, and sometimes as many as 100 times over their six month enrollment. That's ten times more visits than is necessary to post required assignments, and suggests that students use the Message Board discussions as resources and inspiration. Learning may happen while students "lurk," that is, through passively participating in Message Board discussions.

\section{Composed Communication Online}

In the online Shakespeare course, written participation makes for a less spontaneous and sustained but more thoughtful and substantive class discussion than in a F2F situation. An online student explains, "I am a people person, so I could not imagine how a class could function without firsthand discussion. I love discussions, so the thought of participating in a class without that element was daunting. Eventually I realized that this class was the perfect opportunity for me to learn to discuss things in a different way. I had to learn to get used to writing my thoughts down instead of speaking them. I had to learn how to write a post that is both intelligently written, and easy to understand in a discussion format." (KDB)

The value of composed communication works both ways: for the participant who composes such a communication, and thus learns to articulate intuitions in an analytical and persuasive style, and for the rest of the class who benefit from thoughtful and thought-provoking posts. Another online student describes the value of reading other students' contributions: "I really enjoyed being able to 'see' other 
students through their writing. As a person whom (I believe) writes better than she speaks, I find it terribly interesting to observe the thoughts and opinions expressed through a more deliberate, and for the most part more thoroughly considered form of expression. Whether I agreed or disagreed with another student's postings, I felt I was getting a more comprehensive view of his/her thoughts and ideas." (KDB) The high standard of class discourse also dampens repetitive, self-aggrandizing, off-topic and other ephemeral contributions that can plague F2F discussions. One of my online students describes this phenomenon vividly: "I don't like to sound antisocial, but often there is a know-it-all in [F2F] class. In this particular [online] forum, there is less room for the blow hard who feels he will get a better grade simply because he is evermore opining or because he is simply contradictory to every opinion or idea expressed." (KDB)

\section{Universal Participation Online}

Universal participation makes for more diverse contributions to online discussions, including per force those students who would refrain from participation due to a variety of social and personal issues. Written contributions can be liberating for students inhibited by public speaking: "It was easier to type something where people read it than it is to say something aloud in front of people at the risk of being wrong. There is less stress in an online course because social circles don't exist. And if someone is really shy, it is easier to say more online. You can also organize your thoughts better before posting them, whereas in a class room, the conversation may change before you know exactly what you want to say." (KDB)

\section{E. Lively But Slow?}

"I believe our [Message Board] discussions are just as lively [as F2F discussions]," notes one loyal online student, "they are just slower." (KDB) For many, that is an oxymoron. The quick, real time exchange of a class discussion at its best cannot be reproduced in an asynchronous online format. Students post to the message board in an asynchronous fashion, that is, as they are required or inspired at the appropriate moment in their individual progress through the course, a progress not synchronized with other students. Sometimes the messages to which they respond are left by students who have gone on to other parts of the course or even completed the course. When an interlocutor is no longer available, a dialogue is difficult to sustain. Some threads may function not as a conversation among students, but as a collection of individual responses to the instructor. Compared to the spontaneous, rapid pace of a sustained classroom discussion, the asynchronous message boards can feel disjointed and stilted.

I find, however, and so do the majority of my online students, that the high quality of individual contributions and the low frequency of off-topic and trivial contributions in the asynchronous threaded discussions compensate for the loss of exciting and inspirational qualities of a F2F discussion. Moreover, the requirement for all students to complete assignments by posting messages ensures that each student actively participates in class discussion; F2F discussions might be momentarily more entertaining and emotionally satisfying, but they allow many students to remain silent.

\section{OVERALL MIX AND IMPACT OF FOUR COMMUNICATION MODES ONLINE VERSUS F2F}

The structure of the online "Introduction to Shakespeare" class achieves a mix of the four communication modes that maximizes the value of one-to-one and one-to-many communication and minimizes the disadvantages of one-alone and many-to-many in student learning. 
In the two tables below, I present the mix among the four communication modes in the online class versus the F2F class. $71 \%$ of an online students time is spent in the one alone or the one-to-many communication modes; only 55\% of the online student's time is spent in the one alone or one-to-many modes. Fully $31 \%$ of an online student's time is spent in one-to-one communication with me, working on assignments and engaging in a dialogue about his or her work, as opposed to $19 \%$ of the F2F student's time.

\begin{tabular}{|l|l|l|l|}
\hline \multicolumn{5}{|c|}{$\begin{array}{c}\text { Table 2 } \\
\text { (Eng. 17, "Introduction To Shakespeare") }\end{array}$} \\
\hline Mode & Definition & $\begin{array}{l}\text { Est. avg. } \\
\text { hours/student }\end{array}$ & $\begin{array}{l}\text { Percent/ } \\
\text { Total }\end{array}$ \\
\hline One Alone & Reading 5 Shakespeare plays & 20 & $35 \%$ \\
\hline One-to-One & Assignments, Quizzes, Office Hours & 16.5 & $19 \%$ \\
\hline One-to-Many & Listening to Lecture & 30 & $37 \%$ \\
\hline Many-to-Many & Listening to/Contributing to Discussion & 8 & $9 \%$ \\
\hline TOTAL & & 87 & $100 \%$ \\
\hline
\end{tabular}

\begin{tabular}{|c|c|c|c|c|}
\hline \multicolumn{5}{|c|}{$\begin{array}{c}\text { Table 3 } \\
\text { Online: Student Time Spent In Each Communication Mode } \\
\text { (XB17, "Introduction To Shakespeare") }\end{array}$} \\
\hline Mode & Definition & $\begin{array}{l}\text { No. of } \\
\text { Words } \\
\text { (approx.) }\end{array}$ & $\begin{array}{l}\text { Est. avg. } \\
\text { hours/ } \\
\text { student }\end{array}$ & Percent /Total \\
\hline One Alone & Reading 5 Shakespeare plays & 109,096 & 13 & $31 \%$ \\
\hline One-to-One & Assignments, Teacher Feedback & 6,250 & 13 & $31 \%$ \\
\hline One-to-Many & Reading Lecture Notes & 40,000 & 10 & $24 \%$ \\
\hline Many-to-Many & $\begin{array}{l}\text { Reading/ Responding to Message } \\
\text { Boards }\end{array}$ & 34,000 & 6 & $14 \%$ \\
\hline TOTAL & & & 42 & $100 \%$ \\
\hline
\end{tabular}

Given the mix of the modes I describe above, the individual value or impact of each mode of communication changes for my online and F2F "Introduction to Shakespeare" classes. Below are two matrices that compare the impact of the mode mix. The matrices below function as graphic representations of my own conclusions, the evidence and logic for which are developed in the preceding discussions.

\begin{tabular}{|l|l|l|l|}
\hline \multicolumn{4}{|c|}{ Table 4 } \\
Online: Impact of Each Communication Mode (XB17, \\
"Introduction To Shakespeare")
\end{tabular}




\begin{tabular}{|l|l|l|l|}
\hline One-to-Many & & & X \\
\hline Many-to-Many & & X & \\
\hline
\end{tabular}

\begin{tabular}{|l|l|l|l|}
\hline \multicolumn{5}{|c|}{ Table 5 } \\
\multicolumn{2}{|c|}{$\begin{array}{c}\text { F2F: Impact of Each Communication Mode } \\
\text { (Eng. 17, "Introduction To Shakespeare”) }\end{array}$} \\
\hline & Low & Medium & High \\
\hline One Alone & & X & \\
\hline One-to-One & X & & \\
\hline One-to-Many & & X & \\
\hline Many-to-Many & & X & \\
\hline
\end{tabular}

The online version of my "Introduction to Shakespeare" course has consistently better learning outcomes than the on-campus version as a result of the compelling nature of the one-to-one communication mode online and the effectiveness of the many-to-many and one-to-many mode online.

\section{OVERALL STUDENT PERFORMANCE ONLINE VERSUS F2F}

Online "Introduction to Shakespeare" students report high satisfaction, and that the online classroom enables effective and efficient learning. My F2F evaluations are equally positive, but the dramatic difference in student performance suggests that my online students achieved more as measured against the course objectives. The structure of the online class interacts with the qualities of an "adult learner" to result in exceptional learning outcomes.

\section{A. Student Satisfaction and Performance Assessment}

$100 \%$ of online students surveyed indicated that they would recommend my online Shakespeare course to others. (UCBXO) My F2F evaluations don't ask that particular question, but they do ask about my "effectiveness as a lecturer" and my success in "covering the subject matter." Approximately 98\% of those evaluations responded positively to those questions (UCBED), so student satisfaction in both courses was high. The comparable rates of student satisfaction, however, do not translate into comparable student performance.

Course objectives for both classes were the same, with different emphases to reflect the difference in student populations. The course is designed to help students develop:

- A critical perspective on the iconic role of Shakespeare in our culture, a tonic to popular and academic "bardolotry"

- Increased comprehension and ability to analyze the texts of Shakespeare plays (the actual Renaissance language, figurative language and allusions, dramatic structure), especially close reading of the texts

- A concrete sense of the range of cultural and literary issues raised by the plays, in a Renaissance context

- An ability to make connections among the issues raised by the plays and cultural texts, productions and issues in contemporary American culture 
- Increased ability in critical reading of literary texts in general

- Increased ability in writing critical discursive prose

The online class emphasizes connections to contemporary American culture and the students' own cultural interests; the on-campus class emphasizes students' practice of close readings of the texts.

Course objectives were the same; student performance against those objectives, as measured by grade distribution in Table 6, was dramatically different.

\begin{tabular}{|l|r|r|}
\hline \multicolumn{3}{|c|}{$\begin{array}{c}\text { Table 6 } \\
\text { Grade Distribution } \\
\text { "Introduction To Shakespeare" }\end{array}$} \\
\hline & \multicolumn{2}{|c|}{ Pct Total Grades } \\
\hline Grade & F2F & \multicolumn{2}{c|}{ O/L } \\
\hline F & $1 \%$ & $0 \%$ \\
\hline D- & $1 \%$ & $0 \%$ \\
\hline D & $1 \%$ & $0 \%$ \\
\hline D+ & $1 \%$ & $0 \%$ \\
\hline C- & $0 \%$ & $0 \%$ \\
\hline C & $1 \%$ & $0 \%$ \\
\hline C+ & $5 \%$ & $1 \%$ \\
\hline B- & $12 \%$ & $4 \%$ \\
\hline B & $25 \%$ & $10 \%$ \\
\hline B+ & $39 \%$ & $26 \%$ \\
\hline A- & $\mathbf{1 2} \%$ & $\mathbf{3 0} \%$ \\
\hline A & $\mathbf{3} \%$ & $\mathbf{2 8}$ \\
\hline
\end{tabular}

A whopping $58 \%$ of my online students received an A or A-, as opposed to the more usual $15 \%$ of my F2F students. I oversaw the grading or personally graded all the student work and, as dictated by UCBXO policy, applied the same grading standards for both classes over the course of two years. The difference in performance cannot be attributed to changes in graders or grading standards over time. The online Shakespeare class, however, has a $43 \%$ completion rate (i.e., only $43 \%$ of the students who sign up for the class actually complete it); that rate is comparable to national distance education rates and most of the attrition is due to factors outside of the classroom. (Working adults typically overestimate their ability to manage work and home priorities when they enroll in a demanding class.) Even if we reduce the percentage of students receiving A's by $57 \%$ (that is, include putative students in the curve who never completed the class and presumably would not have earned A's), then an impressive $29 \%$ still represents A students, double the rate of outstanding performers in the traditional undergraduate classes.

To a significant degree, my online students achieved more of the course objectives than my F2F students. But those who complete the online class are part of a self-selected group, less than half who actually enroll, who have the motivation and the ability to do well in the course. Attrition and/or self-selection do not limit my F2F students to relatively strong performers; the traditional undergraduate environment supports a high rate of completion regardless of performance. (In fact, we may speculate that in situations 
where students take classes on an elective basis, that the higher the attrition rate, the higher the average performance of those who remain and complete the course.) A completely online, asynchronous literature course necessarily requires and rewards some of the qualities we may expect to find in a successful adult distance education student; the structure of a traditional undergraduate lecture literature course does not.

\section{B. Online Environment Rewards Adult Learning Styles}

I asked seven of my online students from the last 12 months to answer the following question: "Consider your learning overall in the online class and in traditional on-campus classes. Did the differences in format affect your overall learning? In terms of how much and how effectively you learned, would you currently prefer to take an online or a traditional course?" Six answers, not surprisingly coming from successful online students, were very positive about the class and, I think, reflect how their individual learning styles interacted with the inherent structure of the online classroom. (The seventh answered that it would depend on the class, an answer with which it is hard to argue but doesn't add much to this discussion.) (All quotes in this section KDB.)

The online classroom compares favorably with students' F2F classroom experiences:

- "I would sincerely vote for online as this learning style will help me get the "best of all the worlds."

- "I would have to say I believe that I learned more from the online experience than I have in oncampus literature courses."

- "Online classes provide possibilities and measure up to traditional classes."

Announcing in the $J A L N$ that students feel they learn as much or more in an online class as they do in an F2F classroom amounts to old news. More significantly, these comments also demonstrate the personal learning styles of successful online students:

- Self-paced, independent, sets own learning goals, highly motivated: “Online course win, hands down. I cannot keep a normal schedule but am highly motivated. For me it is not solely about the accumulation of credits, but actual learning . . . Even if I had the time and ability to go to a traditional class, I am not certain I would at this point. I have so much enjoyed the online experience."

- Independent, enjoys solitary review of material: "Perhaps due to my personal learning style, I tend to grasp material easier as an independent learner outside of the classroom environment and prefer online courses overall."

- Values composed, textual communication, review; less social, but values some give-andtake: "Overall, I must say I have learned more in the online course I have taken than in similar traditional classes. I made good grades in my traditional classes, but I do not believe the depth of learning was the same. The difference in format only helped me; full lectures and other reading makes a big difference for me. I can safely say that I prefer online classes to traditional ones. While I can't go to the coffee shop with my online classmates, I feel ever so much more comfortable discussing and disagreeing with them through this forum." 
In these comments, the "mature mind," as Malcolm Knowles first called his profile of an adult learner, speaks clearly.

\section{SUMMARY OF CONCLUSIONS}

The structure of the online "Introduction to Shakespeare" class achieves a mix of the four communication modes that maximizes the value of one-to-one and one-to-many modes and minimizes the disadvantages of one-alone and many-to-many communication in student learning.

One Alone: The online course allows students to pace themselves according to their needs vis a vis the material. Fixed-date cohort classes do not allow for self-pacing.

One-To-One: Exchanges between teacher and student generally have high impact on student learning in both online and on-campus environments; in my online class, however, it is the requisite mode for our communication, whereas in the on-campus class, direct communication with me was optional. Moreover, all one-to-one communication online occurs as text. The act of composing responses to course content makes one-to-one communication online more substantive than ephemeral in-person encounters. As a result, this mode offers higher value for my online Shakespeare students than those in the F2F classroom.

One-To-Many: My on-campus students actually spend 35\% more time on "Introduction to Shakespeare" lectures than do their online counterparts; however, the online students do not report significantly less comprehension of or engagement with the content of my lectures and other one-to-many communications. The "entertainment value" of F2F lectures is supplemented online by what we might call the inherent "reference value" of one-to-many communication, that is, its continuous availability to the student for review and reflection. Moreover, the time online students report spending on course work is purely focused time spent reading and responding to the texts, lecture notes, message board postings and working on assignments. Face time as a measure of active F2F student engagement needs to be discounted according to how much of it might represent higher quality focused time. Focused time represents more efficient use of student time, and makes the teacher's one-to-many communication more effective.

Many-To-Many: The high quality of individual contributions and the low frequency of off-topic and trivial contributions in the asynchronous threaded discussions compensate for the loss of exciting and inspirational qualities of a F2F discussion. Moreover, the requirement for all students to complete assignments by posting messages ensures that each student actively participates in class discussion. F2F discussions might be momentarily more entertaining and emotionally satisfying, but they are necessarily defined by a lower standard of discourse and allow many students to remain silent.

Online "Introduction to Shakespeare" students report that the online classroom enables effective and efficient learning. My F2F evaluations are equally positive, but my online students achieve dramatically better performance as measured by grade distribution. The structure of the online class interacts with the qualities of an "adult learner" to result in exceptional learning outcomes. Ultimately, the differences between the online and F2F classrooms may be less crucial to learning outcomes than the degree to which the course design, regardless of technological environment, develops and supports students' abilities to practice adult learning styles. 


\section{AN ACCIDENTAL POLEMIC}

I'd like to add an unintentionally polemical post-script to my conclusions, in an effort to come clean, as it were, with the theoretical biases to my practical experiment in teaching "Introduction to Shakespeare" both online and F2F.

My conclusion that the structure of my online Shakespeare course interacts with and intensifies the salience of adult learning styles and therefore, the effectiveness of student-centered and andragogical teaching practices, was a discovery for me. It was Newton's apple. Then, a bit of preliminary research on my part uncovered an orchard of the same apples falling on a cohort of theoretically savvy and experienced instructors. My "discovery" represents a widely held consensus that an online classroom has a structural bias toward student-centered learning among knowledgeable online teachers and course designers in education at all levels, not only in adult education.

My research also introduced me to critical perspectives on Knowles's use of self-direction as a culturally and chronologically universal description of the adult learner [3]. That critique, it seems to me, demonstrates that the current orthodox pedagogy of adult education and by extension, of online education, does not entirely succeed as an objective, trans-cultural theoretical framework. Instead, our pedagogy consists of a set of social values, aspirations to a frankly Jeffersonian ideal expressed through theories of teaching and learning. The adult learner is less an a priori demographic profile of students, a phenomenological description of learning, than it is an individual goal achieved by students to varying degrees in collaboration with their teacher as the course proceeds. This ethical rather than theoretical principle may deviate from the discipline of education as a social science, nor can it be applied to all students in all stages of their lives in all kinds of classes everywhere. Nonetheless, I personally do not find anything wrong with the concept-and hope - that my teaching can help students continue the process of becoming self-directed, reflective, joyful, life-long learners.

My belief that the principles of adult learning and the structure of the online classroom reinforce each other has therefore turned into an accidental polemic: Effective course design and teaching practices-in both an online and traditional F2F classroom-support students' progress toward the Knowlesian ideal of an adult learner. The structural bias I have found in my UCBXO online classrooms is reciprocated by a similar tendency in my own teaching, shaped by and simultaneously shaping an aspiration toward that ideal in myself and for my students.

\section{ABOUT THE AUTHOR}

Mary Ann Koory has her Ph.D. in English Literature and has published and presented papers on the poetry of John Donne, the plays of Shakespeare, various aspects of mystery fiction and the pedagogical use of online technology. She currently teaches two online courses for the University of California Berkeley Extension Online, both of which have received the Helen Williams National Award for Excellence in Collegiate Independent Study, awarded by the American Association for Collegiate Independent Study. She received the Alfred P. Sloan Foundation Consortium 2002 Award for Excellence in Asynchronous Learning Networks Teaching and this year was named "Honored Instructor" by U.C. Berkeley Extension. She recently completed writing and designing an online workshop for new UCBXO online instructors that is due to open later this year. She welcomes comments at bardunex@earthlink.net. 


\section{REFERENCES}

1. Paulsen, Morten Flate. "Computer Mediated Communication and the Online Classroom," Distance Learning, Vol. III, eds. Zane L. Berge and Mauri P. Collins; Cresskill, N.J.: Hampton Press, 1995.

2. Meyer, Katrina A. "The Web's Impact on Student Learning," Technological Horizons in Education Journal Online, May 2003. http://www.thejournal.com/magazine/vault/A4401.cfm

3. Brookfield, Stephen. "Adult Learning: An Overview," in A. Tuinjman, International Encyclopedia of Education, Oxford: Pergamon Press, 1995.

http://www.nl.edu/ace/Resources/Documents/AdultLearning.html 